\title{
Molecular Weight Distribution Analysis of Pyrolysis Oils by Gel Permeation Chromatography
}

Anne E. Harman-Ware (Liz)*, Jack R. Ferrell III ACS $260^{\text {th }}$ National Meeting: San Francisco, CA Symposium: Reliable Analytical Techniques of Biomass-derived products symposium

August 17, 2020 


\section{Contents}

1 Background

2 Production and Methodology

3 Bio-oil Properties

4 GPC Detection Comparison

5 Summary

6 Future Directions

7 Thanks and Funding 


\section{Background - Bio-oil}

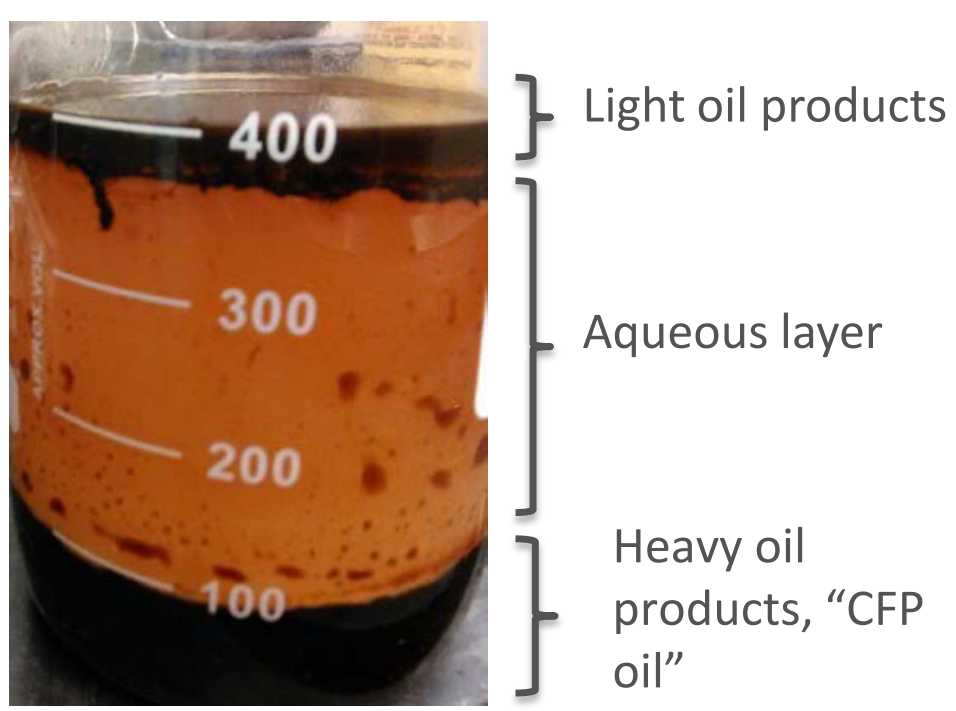

thermal decomposition of biomass in the absence of oxygen

- Highly complex - analytes come from different components in biomass (lignin, sugars, etc.)

- Not stable, "ages"

- $\quad$ Catalytic fast pyrolysis (CFP) bio-oil: fast pyrolysis oil produced in the presence of a catalyst

- "Upgrade" in composition and properties

- Often reduction in oxygenation, still complex - All bio-oils are difficult to characterize!

Harman-Ware, A. E.; Ferrell, J. R., Characterization of catalytic fast pyrolysis oils: The importance of solvent selection for analytical method development. Journal of Analytical and Applied Pyrolysis 2018, 132, 190-199.

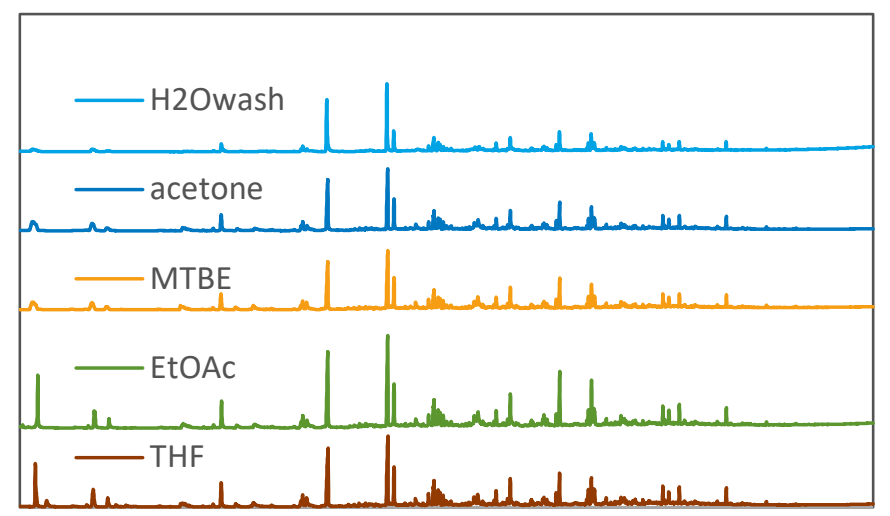




\section{Background - GPC}

Gel Permeation Chromatography (GPC): separation of analytes on the basis of hydrodynamic volume ( size) using porous beads as stationary phase; used to determine molecular weight of polymers (weight average molecular weight, Mw; number average molecular weight, $\mathbf{M n}$, etc.)

- Often calibrated against standard polymers that should be representative of samples

- Uses different types of detectors: UV$D A D$, refractive index, light scattering, viscosity

Harman-Ware, A. E.; Ferrell, J. R., Methods and Challenges in the Determination of Molecular Weight Metrics of Bio-oils. Energy \& Fuels 2018, 32 (9), 8905-8920
Bio-oil molecular weight metrics (distribution, Mw, $\mathrm{Mn}$, etc.) provides insight to properties of oil and conversion conditions necessary to produce oils of optimal properties for use as fuel or chemical feedstocks
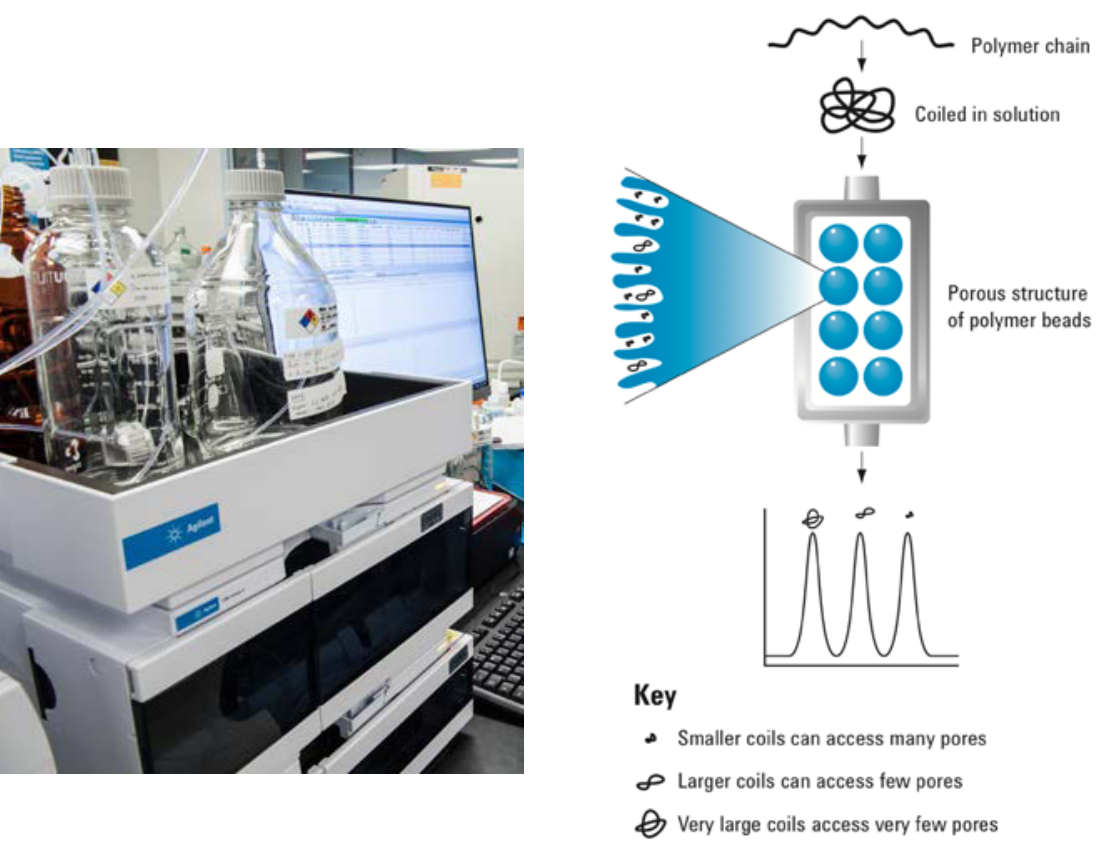

Harman-Ware, A. E.; Orton, K.; Deng, C.; Kenrick, S.; Carpenter, D.; Ferrell, J. R., Molecular weight distribution of raw and catalytic fast pyrolysis oils: comparison of analytical methodologies. RSC Advances 2020, 10 (7), 3789-3795. 


\section{Background - MALS}

- Multi-angle laser light scattering detector

- Intensity of light scattered is proportional to molar mass

- Doesn't require external calibrants for elution volume to molar mass

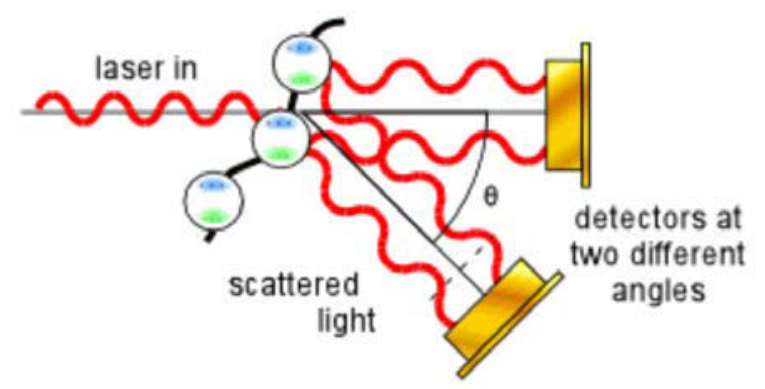
conversion

- Still requires concentrationdependent detector and has limitations

GPC-MALS/RI/visc may provide new or different insights related to bio-oil molecular weight analyses 


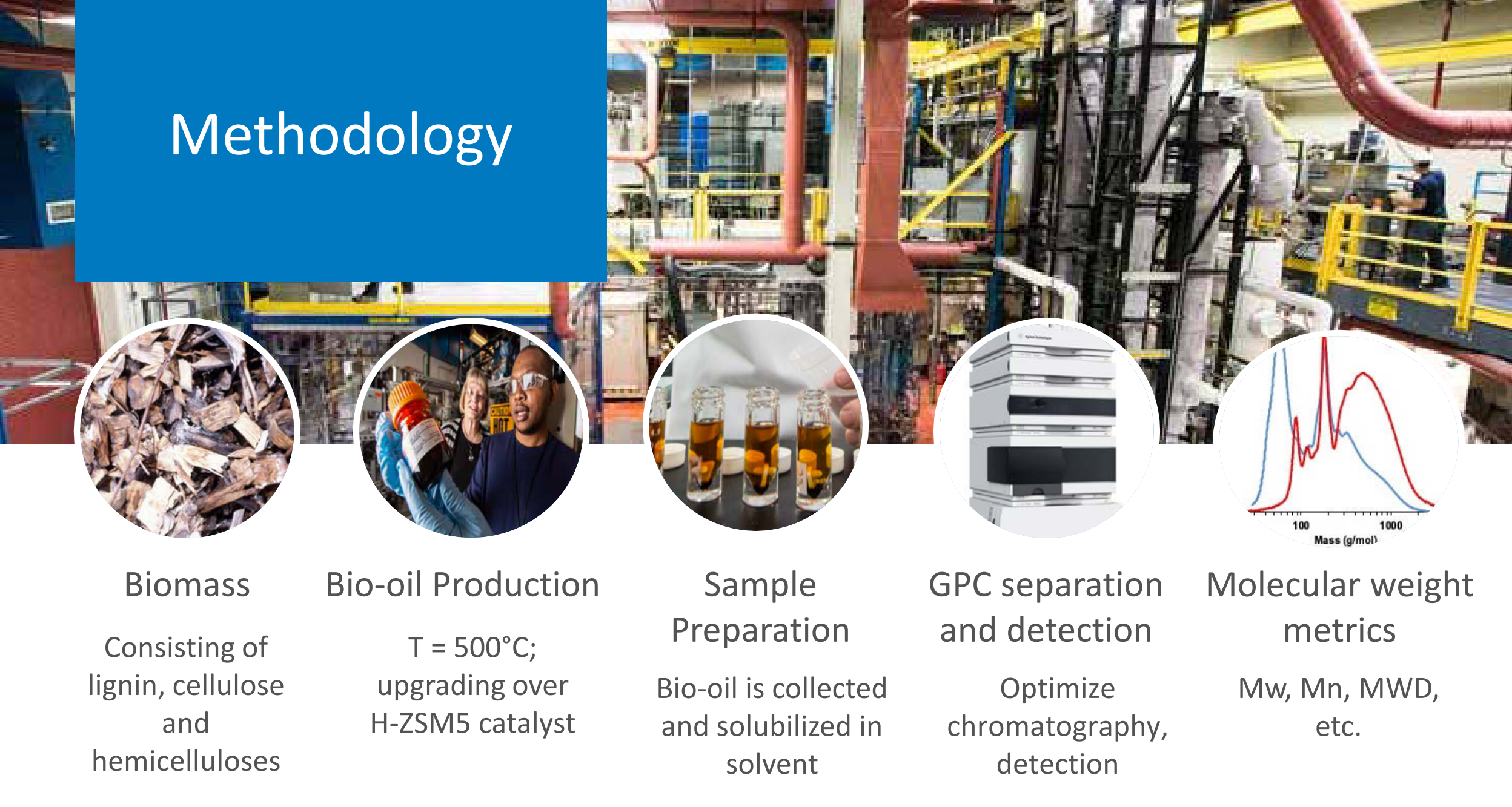


Bio-oil Properties - functional groups, compound classes, viscosity, water content, $\mathrm{CHO}$ content amongst most important

CFP - less oxygen, less water, less viscous, more components detectable by $\mathrm{GC} / \mathrm{MS}$ in comparison to FP

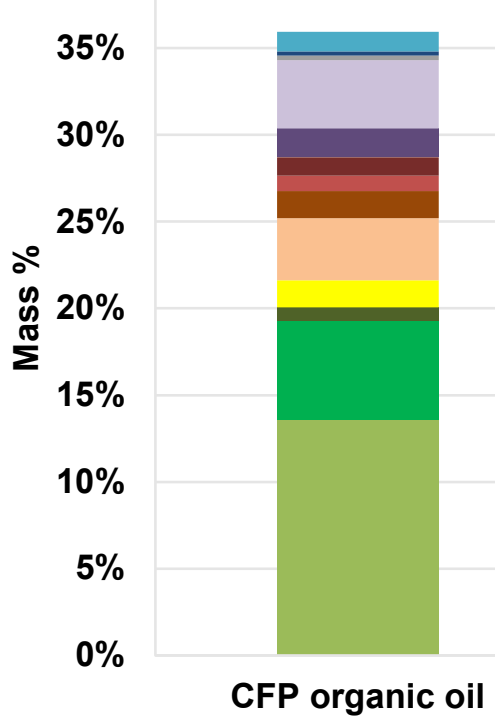

Unknown

- Other OX

Sugars

Methoxyphenols

- Indenols/naphthols

- Other Carbonyls

- Cyclopentenones

- Furanics

Alkylphenols

Phenol

3-Ring Aromatics

2-Ring Aromatics

1- Ring Aromatics/HC

\begin{tabular}{|c|c|c|c|c|c|c|c|c|c|c|c|c|}
\hline Bio-oil & $\mathrm{C}=\mathrm{O}(\%)$ & $\begin{array}{l}\text { Aromatic } \\
\text { C-O (\%) }\end{array}$ & $\begin{array}{l}\text { Aromatic } \\
\text { C-C (\%) }\end{array}$ & $\begin{array}{l}\text { Aromatic } \\
\mathrm{C}-\mathrm{H}(\%)\end{array}$ & $\begin{array}{l}\text { Aliphatic } \\
\text { C-O (\%) }\end{array}$ & $\begin{array}{l}\text { Methoxyl } \\
\text { (\%) }\end{array}$ & $\begin{array}{l}\text { Aliphatic } \\
\text { C-C (\%) }\end{array}$ & $\begin{array}{l}C \\
(\%)\end{array}$ & $\begin{array}{l}H \\
(\%)\end{array}$ & $\begin{array}{l}0 \\
(\%)\end{array}$ & $\begin{array}{l}\text { KF } \\
\text { water } \\
(\%)\end{array}$ & $\begin{array}{l}\text { Intrinsic } \\
\text { viscosity } \\
(\mathrm{mL} / \mathrm{g})\end{array}$ \\
\hline FP oil & 13.8 & 13.3 & 11.8 & 20.5 & 20.6 & 2.6 & 17.4 & 58.6 & 6.7 & 34.6 & 17.3 & $2.99( \pm 0.04)$ \\
\hline CFP oil & 6.7 & 14.8 & 13.5 & 42.1 & 4.1 & 1.9 & 17.1 & 75.4 & 7.0 & 17.3 & 4.8 & $2.42( \pm 0.05)$ \\
\hline
\end{tabular}

Properties of FP and CFP oils obtained from ${ }^{13} \mathrm{C}$ NMR and $\mathrm{CHO}$ analyses (\% values reported on moisture free basis) as well as intrinsic viscosity, $[\eta]$ determined by viscometry with standard deviation of triplicate analyses. 

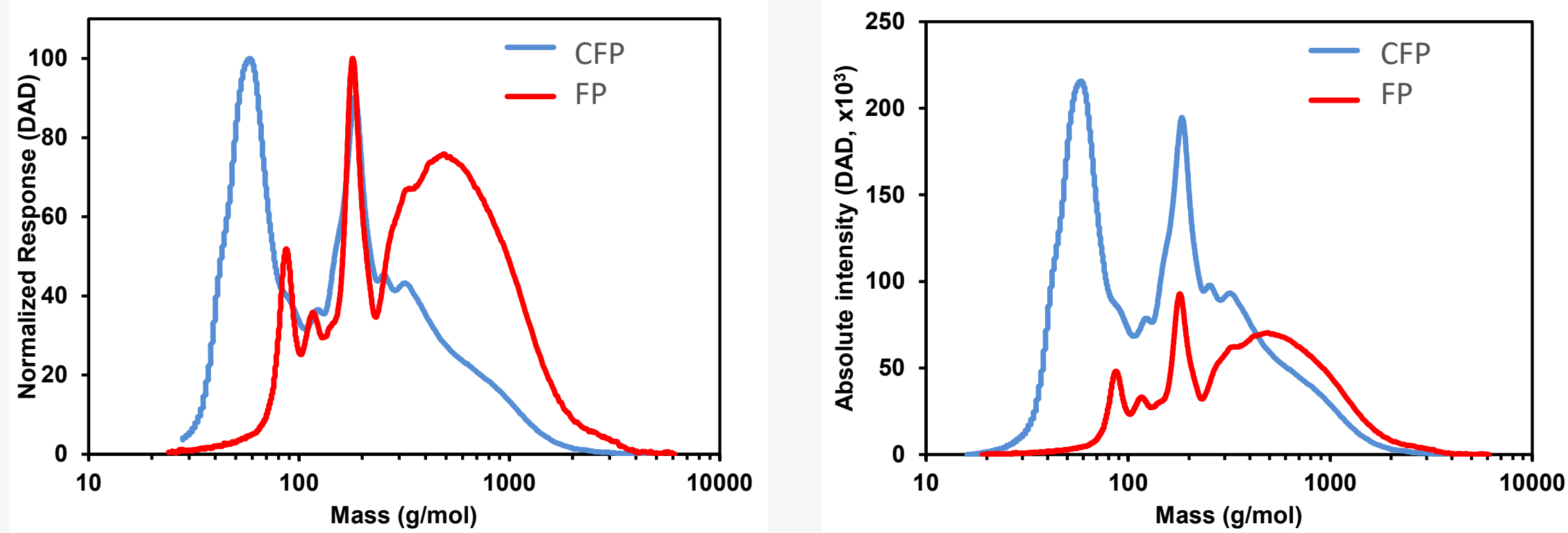

FP oil has higher MW than CFP oil based on UV/DAD detection
Comparison of intensity on consistent concentration basis indicates differences in abundance and detection of species over range of elution volumes ( $\mathrm{g} / \mathrm{mol}$ relative to polystyrene) 

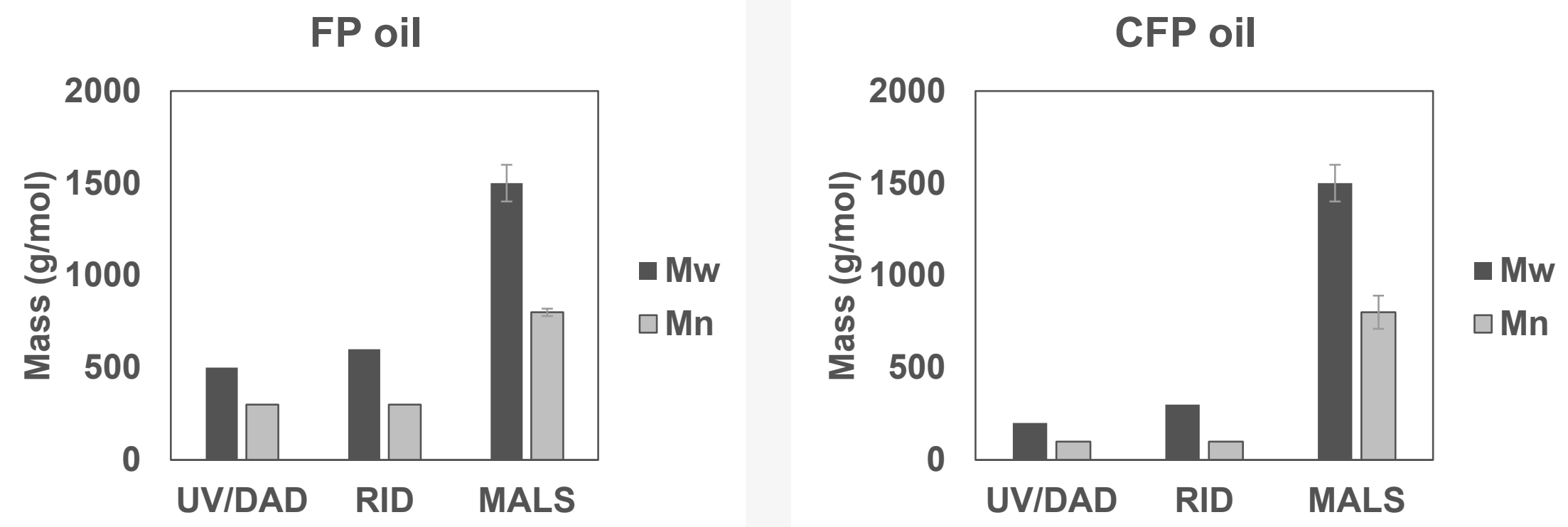

MALS consistently gives higher Mw, Mn followed by $R I$ and UV/DAD
Difference between FP and CFP oils MWD is significant based on UV/DAD (which depends on functionality!) as well as RI relative to polystyrene standards, MALS shows similar Mw, Mn for CFP and FP oils 

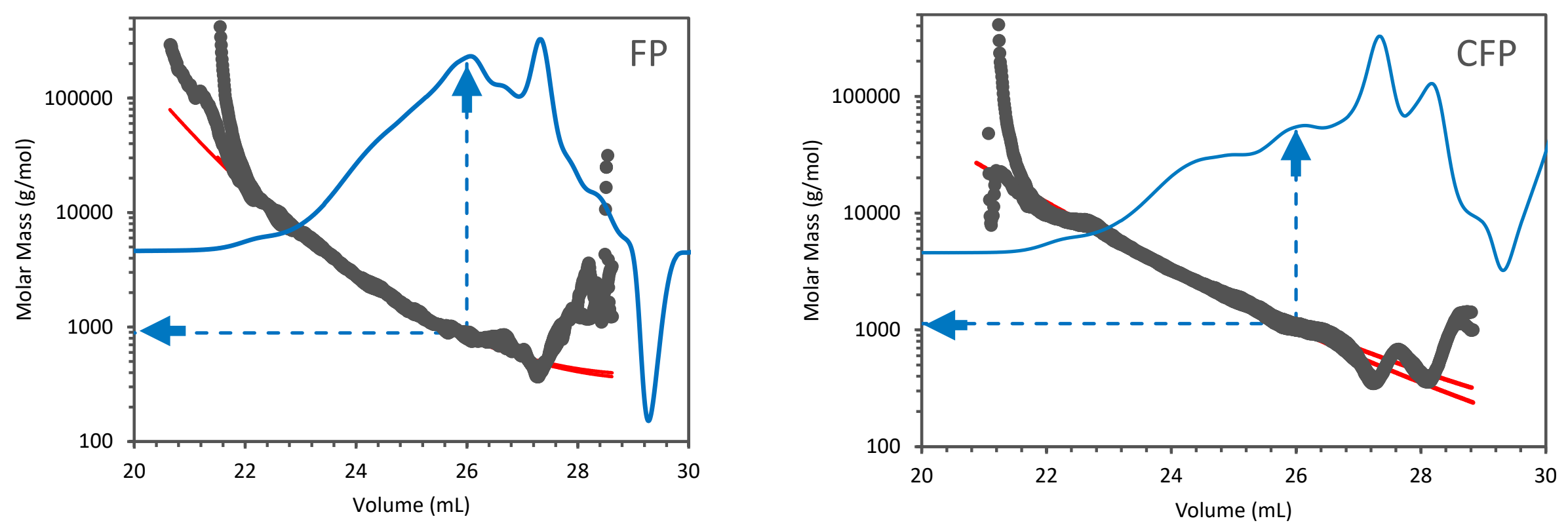

MALS/RI/Visc implies components eluting are larger in comparison to polystyrene calibration

Concentration-dependent RI coupled with universal detection MALS shows higher abundance of larger components in FP oil and higher abundance of smaller components in CFP oil (similar to UV/DAD) 

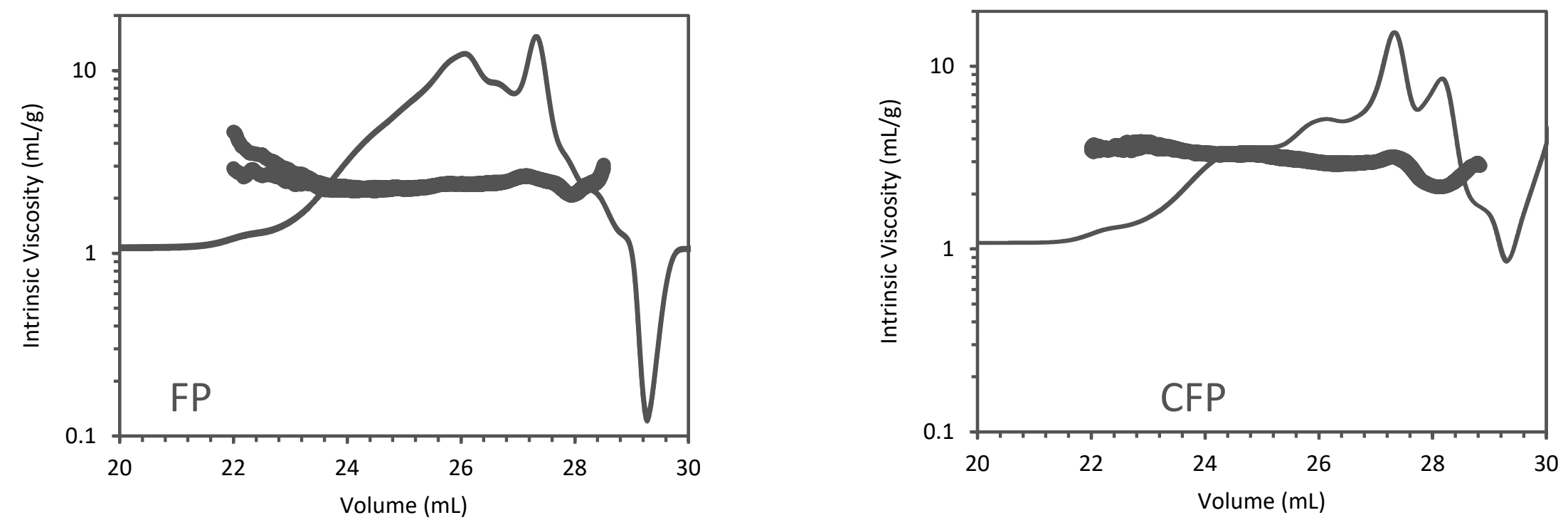

Minor changes in intrinsic viscosity over course of elution
Consistent intrinsic viscosity means more reliable MALS data - provides comparison insights (especially related to Mark-Houwink parameters and universal calibration!) and other information about polymers 

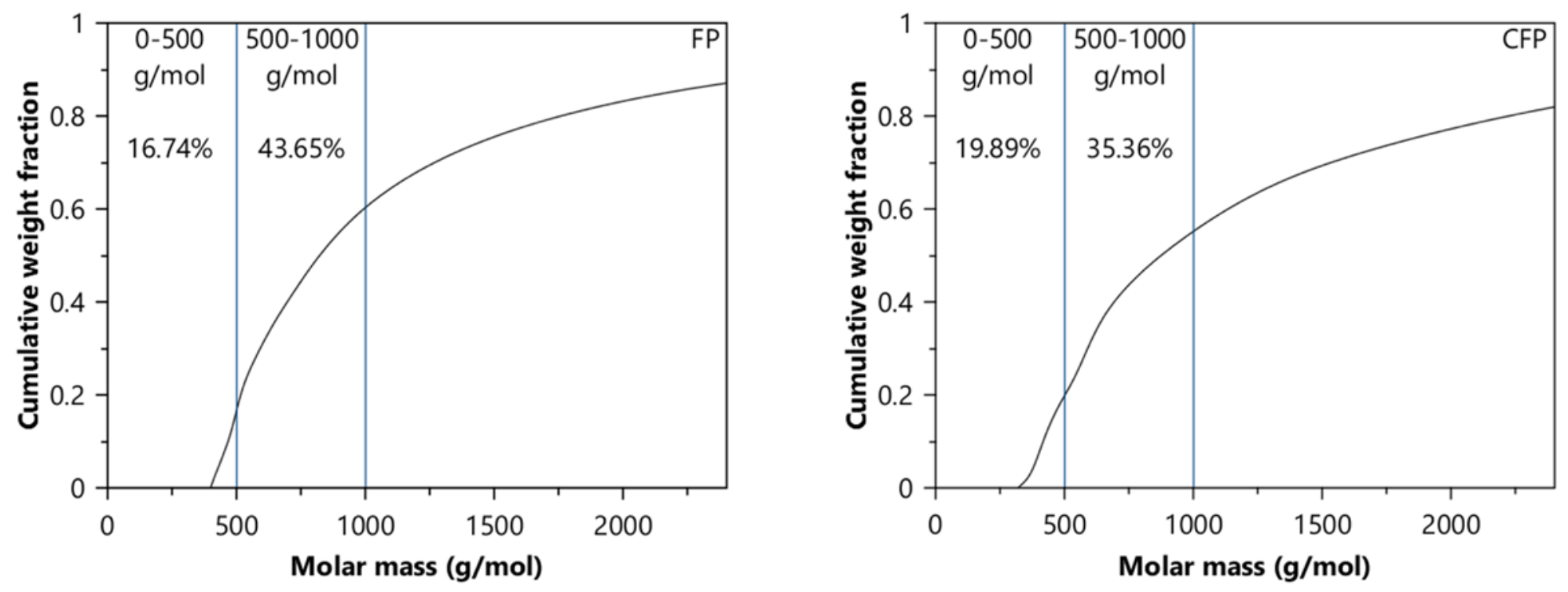

\section{Weight fraction distribution differences from MALS/RI/Visc}

Remaining high MW fraction from FP: 39.61\%

Remaining high MW fraction from CFP: $44.75 \%$ Low MW not detected by MALS, complicated in RI based on signal 


\section{Summary and Conclusions}

Harman-Ware, A. E.; Orton, K.; Deng, C.; Kenrick, S.; Carpenter, D.; Ferrell, J. R., Molecular weight distribution of raw and catalytic fast pyrolysis oils: comparison of analytical methodologies. RSC Advances 2020, 10 (7), 3789-3795.

- More detectors better for method development...

- UV/DAD - only chromophores

- RI - sensitivity and baseline issues

- MALS - low MW issues

- FP vs CFP - property differences impact ability to compare and analyze accurately (differences in intrinsic viscosity and functionality make traditional GPC with elution standards and the common use of UV/DAD only not very accurate)

- FP vs CFP - lower molecular weight expected and apparent for CFP 


\section{Future Directions}

- Improvement in chromatography/resolution

- Expansion of oil composition and property analysis - FTICRMS, GPC-MS

- Physical separation of oil components and subsequent analysis

- Pipe dream: standardization of robust, adaptable methodology 


\section{Thank you!}

Thanks to: Steve Deutch, Renee Happs, Stuart Black, Anne Starace, Jessica Olstad, Crissa Doeppke, Scott Palmer and Rick French. Photos by Dennis Schroeder and Art Wiselogel.

NREL/PR-2800-77575

\section{Funding}

This work was authored by the National Renewable Energy Laboratory, operated by Alliance for Sustainable Energy, LLC, for the U.S. Department of Energy (DOE) under Contract No. DE-AC36-08GO28308. Funding provided by the U.S. Department of Energy Office of Energy Efficiency and Renewable Energy Bioenergy Technologies Office (BETO), and by the U.S. Department of Energy Office of Science, Office of Biological and Environmental Research through the Center for Bioenergy Innovation (CBI), a DOE Bioenergy Research Center. The views expressed in the article do not necessarily represent the views of the DOE or the U.S. Government. The U.S. Government retains and the publisher, by accepting the article for publication, acknowledges that the U.S. Government retains a nonexclusive, paid-up, irrevocable, worldwide license to publish or reproduce the published form of this work, or allow others to do so, for U.S. Government purposes. 


\section{GPC Methodology}

\section{Detailed \\ Information}

Harman-Ware, A. E.; Orton, K.; Deng, C.; Kenrick, S.; Carpenter, D.; Ferrell, J. R., Molecular weight distribution of raw and catalytic fast pyrolysis oils: comparison of analytical methodologies. RSC Advances 2020, 10 (7), 3789-3795.

\section{Pyrolysis oil production}

"Bio-oil samples were solubilized at $1 \mathrm{mg} / \mathrm{mL}$ in tetrahydro- furan (THF). GPC analysis using RI and UV-DAD (or referred to as simply UV) was performed using an Agilent 1200 HPLC with 3 GPC columns (Agilent, $300 x$ $7.5 \mathrm{~mm}$ ) packed with $10 \mathrm{~mm}$ polystyrene-divinyl benzene copolymer gel beads with nominal pore diameters of $10^{4}, 10^{3}$ and $50 A^{\circ}$. The UV-DAD measured absorbance at $270 \mathrm{~nm}$ ( $80 \mathrm{~nm}$ bandwidth). An injection volume of $20 \mathrm{~mL}$ was used with an eluent (THF) ?low rate of $1.0 \mathrm{~mL} \min 1$ for a total run time of 45 min. Polystyrene standards (Agilent Technologies) were used to calibrate for relative $\mathrm{Mw}$ and $\mathrm{Mn}$, with assumptions of Mark-Houwink parameters for relative comparison only. GPC analysis using MALS coupled with differential RI and viscometry analysis was performed using the same chromatographic method and columns described for UV detection. A Wyatt DAWN HELEOS II detector with a $785 \mathrm{~nm}$ MALS was used with a Wyatt ViscoStar III viscometer and Wyatt Optilab T-rEX differential refractometer (RI) with $785 \mathrm{~nm}$ LED. Data were collected and processed using ASTRA 7 for molecular weight analysis."

"Ex situ catalytic pyrolysis was conducted in a dual fluidized bed reactor system 23 using a ZSM- 5 catalyst from Zeolyst (CBV 3024E), silica-to-alumina ratio of 30, sized 300-1000 mm after the original extrudates were ground and sieved. Biomass was fed into the pyrolysis reactor $(5.2 \mathrm{~cm}$ inner diameter $\times 43 \mathrm{~cm}$ height) at a rate of $420 \mathrm{~g} / \mathrm{h}$ over a $200 \mathrm{~mL}$ bed of silica sand. A cyclone separator was used to remove char from the stream allowing the pyrolysis vapors to enter the upgrading reactor $(5.2 \mathrm{~cm}$ inner diameter $\times 15 \mathrm{~cm}$ tall lower section and a $7.8 \mathrm{~cm}$ diameter $\times 35.6 \mathrm{~cm}$ disengagement section). The ZSM- 5 catalyst was metered into the upgrading reactor at a rate of 300 $\mathrm{g} / \mathrm{h}$ and removed continuously via an overflow tube. A stainless- steel mesh hot gas filter was used to filter gases and upgraded vapors and then the vapors were condensed using various collectors including an air-cooled condenser, an electrostatic precipitator, dry-ice traps, and a coalescing filter. Nitrogen was used as the carrier gas during experiments at a flow of $17.4 \mathrm{~L} / \mathrm{min}$ and total flow through the system was measured using a dry test meter. The pyrolysis temperature was $500 \mathrm{C}$, while the upgrading temperature was $550 \mathrm{C}$." 


\section{Additional data}

\begin{tabular}{|l|l|}
\hline GC/MS calibration Compound & $\begin{array}{l}\text { Concentration } \\
\text { (mg/mL) }\end{array}$ \\
\hline Acetaldehyde & $0.05-1.0$ \\
\hline Benzene & $0.05-1.0$ \\
\hline n-octane & $0.10-2.0$ \\
\hline 1-octene & $0.05-1.0$ \\
\hline cis-1,4-dimethyl-cyclohexane & $0.10-2.0$ \\
\hline Toluene & $0.05-1.0$ \\
\hline p-Xylene & $0.10-2.0$ \\
\hline n-decane & $0.10-2.0$ \\
\hline 2-Cyclopentenone & $0.05-1.0$ \\
\hline Benzene, propyl- & $0.05-1.0$ \\
\hline Phenol & $0.05-1.0$ \\
\hline 2,3- Benzofuran & $0.05-1.0$ \\
\hline Indene & $0.05-1.0$ \\
\hline o-Cresol & $0.05-1.0$ \\
\hline o-Methoxyphenol & $0.05-1.0$ \\
\hline Tetralin & $0.10-2.0$ \\
\hline Naphthalene & $0.05-1.0$ \\
\hline Phenanthrene & $0.05-1.0$ \\
\hline
\end{tabular}
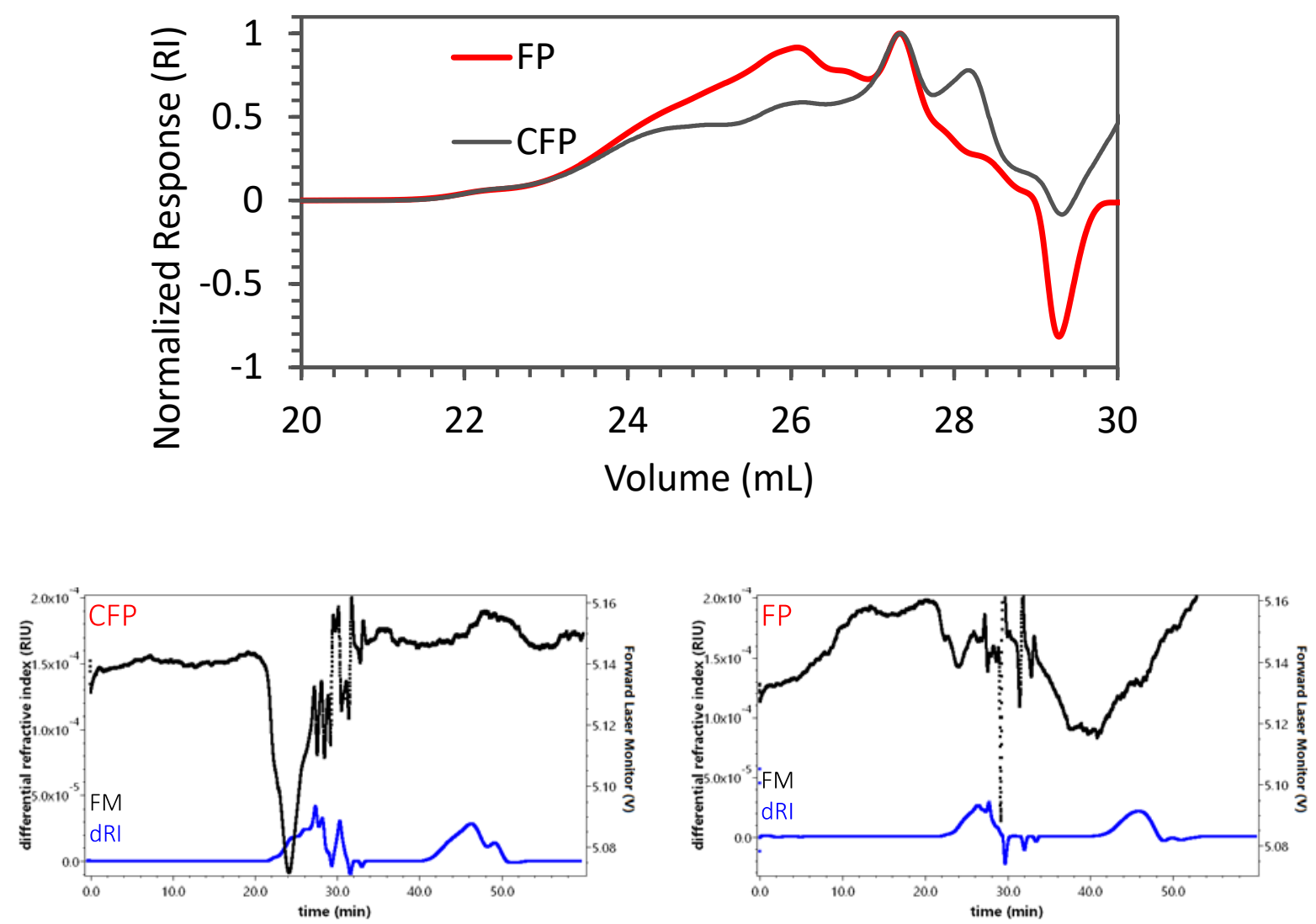